\title{
Editorial: O pesquisador e a pesquisa em ciências criminais na contemporaneidade
}

\author{
Editorial: The researcher and the research in criminal \\ sciences in contemporaneity
}

Caíque Ribeiro Galícia ${ }^{1}$

Doutorando em Ciências Criminais na PUCRS - Porto Alegre/RS

Editor-assistente da RBDPP

caiquerg@hotmail.com

lattes.cnpq.br/2192755380515999

orcid.org/0000-0003-4306-5261

p publons.com/a/1193081

Resumo: O presente editorial apresenta uma anál ise geral da realidade contemporânea do pesquisador e da pesquisa em ciências criminais no Brasil. Busca-se traçar o perfil do(a) pesquisador(a) como um importante componente da compreensão das escolhas de pautas de pesquisa em ciências criminais com enfoque para a superação da falsa pretensão de imparcialidade do sujeito-pesquisador. Nesse panorama, é feita uma análise da pesquisa jurídica no Brasil, destacando sua importância na compreensão mais técnica do Direito, mas também como fato de desenvolvimento social, cultural, político e econômico.

Palavras-chave: editorial; pesquisa jurídica; pesquisador contemporâneo; ciências criminais.

ABSTRACT: This editorial presents a general anal ysis of the contemporary real ity of the researcherandresearch in criminal sciences in Brazil. The researcher's profile is sought as an important component to understand the choices of criminal science research guidelines, with a focus on overcoming the false claim of impartiality of the subject-researcher. In this panorama, an analysis of legal research in Brazil is made, highlighting the most important role in the better

1 Bolsista da PDSE/CAPES - Edital no 19/2016. Processo nº 88881.133417/2016-01 
understanding of legal science, but also as a factor of social, cultural, political and economic development.

KEY-WORDS: editorial; legal research; contemporary researcher; criminal science.

Qualquer reflexão que pretenda abordar o pesquisador e a pesquisa científica em ciências criminais deve levar em consideração uma dupla dimensão de análise: o contexto social, político e econômico do locus da pesquisa e do pesquisador (espaço) e as condições gerais ou estado da arte do pensamento em desenvolvimento no momento (tempo) como dinâmicas em constante mutação ${ }^{2}$. A proposta de análise desde a reflexão do espaço e do tempo do processo de produção científica, e com isso a tomada de consciência da complexidade ${ }^{3}$ ínsita a esse processo, é relevantíssima para auxiliar a compreensão do panorama contemporâneo em torno do pesquisador e da pesquisa em ciências criminais no Brasil.

Não é necessário muito esforço para identificar algumas entre tantas dificuldades no desenvolvimento da pesquisa científica no Brasil. Aliás, no caso específico do campo das ciências jurídicas, as atividades e os atores envolvidos (pesquisadores, pós-graduandos, professores, etc.) com a produção de conhecimento são, além de recentes ${ }^{4}$, na maioria das

2 A relação espaço-tempo como condição indissociável da análise aqui pretendida segue o paradigma contemporâneo segundo o qual "[a] antiga ideia de um universo em essência imutável que pudesse ter existido e pudesse continuar a existir foi substituída para sempre pela ideia de um universo dinâmico e em expansão" (HAWKING, Stephen. Uma breve história do tempo. Rio de Janeiro: Intrínseca, 2015. p. 53).

3 A ideia de um princípio de complexidade, de acordo com Edgar Morin, se traduz no esforço "por abrir e desenvolver amplamente o diálogo entre ordem, desordem e organização, para conceber, na sua especificidade, em cada um dos seus níveis, os fenômenos físicos, biológicos e humanos”, sendo que se deve "insistir fortemente na utilidade de um conhecimento que possa servir à reflexão, meditação, discussão, incorporação por todos, cada um no seu saber, na sua experiência." (MORIN, Edgar. Ciência com consciência. Rio de Janeiro: Bertrand Brasil, 2010. p. 30).

4 Segundo Balbachevsky, os atuais cursos de pós graduação no Brasil têm sua origem no "modelo das cátedras, adotado nas primeiras universidades brasileiras criadas nos anos 1930.” (BALBACHEVSKY, Elizabeth. A pós-graduação 
vezes fruto de um duplo processo que varia entre o aprofundamento científico aliado com afastamento da realidade social (puramente teórico) ou, por outro lado, concentrado na prática dos tribunais e/ou demais instituições e, por vezes, desprovido de caráter científico (puramente prático) ${ }^{5}$.

No Direito e, mais especificamente, nas ciências criminais, esse fenômeno é bastante sintomático, e sobretudo para quem vive a rotina da pesquisa científica se mostra evidente a dificuldade de conformação entre a teoria e a prática forense brasileira. A pergunta "e na prática, como funciona?" é o enfrentamento cotidiano de qualquer pesquisador-professor, normalmente seguida de uma resposta variando entre otimismo e pessimismo, ambos fantasiosos e pouco úteis para o progresso do conhecimento jurídico.

Mas por que a pesquisa científica jurídica tendencialmente gera esse distanciamento da prática diária dos tribunais brasileiros? Por que é tão difícil explicar - e entender - essa dissonância muitas vezes esquizofrênica? Quais são as origens dessa diferença tão grande e agoniante?

Qualquer tentativa de procurar um argumento único de explicação se igualaria aos trabalhos herculanos, além de possivelmente permanecer na superficialidade diante das múltiplas manifestações do problema. Isso porque esse fenômeno se apresenta em diferentes dimensões não excludentes, mas que se complementam nas diversas explicações: desde a elitização daqueles que historicamente tiveram acesso aos centros de produção de conhecimento científico e de tomadas de decisões ${ }^{6}$, até questões atinentes aos aspectos políticos, financeiros e também culturais em determinando momento histórico.

O pesquisador jurídico brasileiro, de maneira geral, foi formado em um ensino básico acrítico e formatador ${ }^{7}$, reduzindo os potenciais

no Brasil: novos desafios para uma política bem-sucedida. In: BROCK, Colin. SCHWARTZMAN, Simon (org). Os desafios da educação no Brasil. Rio de Janeiro: Editora Nova Fronteira, 2005. p. 276).

5 BOURDIEU, Pierre. Poder simbólico. Lisboa: Edições 70, 2016. p. 226.

6 HOLANDA, Sérgio B. Raízes do Brasil. São Paulo: Companhia das Letras, 2014. p. 185-200.

7 Para Finkel, é necessário aprender os feitos sobre o mundo para poder circular sobre ele, sendo que apenas absorver informação específica - como normalmente é ensinado - não é adequado, aliás, a educação deveria servir para a busca por aprendizado de longa duração que altere a nossa apreciação 
individuais para ser encaixado/enquadrado ${ }^{8}$ no padrão profissional que o mercado sempre preferiu e que é etapa necessária para cursar o ensino superior, além de refletir uma determinada estrutura vertical da sociedade $^{9}$, verdadeiras heranças históricas ${ }^{10}$. A universidade geralmente reproduz essa mesma lógica, normalmente voltada para a utilidade e/ou eficiência prática exigida pelo mercado profissional, e em poucos casos conta com um projeto pedagógico efetivamente centrado na produção de conhecimento científico, fato mais evidente no caso das instituições privadas $^{11}$, que correspondem à maioria dos cursos de Direito no Brasil.

Interessante notar que, embora exista um comando constitucional (art. 207, CF/88) que expressamente trate da indissociabilidade entre ensino, pesquisa e extensão, a realidade brasileira ainda está muito distante dessa "indissociabilidade". E para evidenciar esse contraste, de acordo com a plataforma GeoCAPES, atualizada com dados de 2013, o número de pós-graduandos (considerando todas as áreas do conhecimento) totalizavam $347.035^{12}$ matriculados e titulados, em uma população de $190.755 .799^{13}$ brasileiros, o que significa a assustadora porcen-

do mundo, aprofundando-a, ampliando-a, generalizando-a e aprimorando-a (FINKEL, Don. Dar classe con la boca cerrada. Valência: Publicacions de la Universitat de Valência, 2000. p. 37).

8 GIACOMOLLI, Nereu. Pensar, aprender e transmitir Direito Processual Penal. Boletim Informativo IBRASPP, Porto Alegre, n. 07, 2014.

9 A crítica de Baratta é certeira quando afirma que o "sistema escolar, no conjunto que vai da instrução elementar à média e à superior, reflete a estrutura vertical da sociedade e contribui para cria-la e para conservá-la, através de mecanismos de seleção, discriminação e marginalização" (BARATTA, Alessandro. Criminologia crítica e Crítica do Direito Penal. Introdução à sociologia do Direito Penal. Rio de Janeiro: Revan, 2014. p. 172).

10 ALFONSO-GOLDFARB, Ana Maria. FERRAZ, Márcia H. M. Raízes históricas da difícil equação institucional da ciência no Brasil. São Paulo em Perspectiva, vol. 16, $\mathrm{n}^{\mathrm{O}} 3,2002$.

11 De maneira geral, a contribuição da pesquisa científica no Direito não gera retorno financeiro para instituição como as vezes ocorre na área da Saúde (produção de remédios, técnicas inovadoras, etc.) ou Exatas (novas tecnologias na cibernética, na construção civil, etc.).

12 Disponível em: <https://geocapes.capes.gov.br/geocapes/\#>. Acesso em 26 jul. 2017.

13 Disponível em: <http://censo2010.ibge.gov.br/resultados.html>. Acesso em 26 jul. 2017. 
tagem de $0,18 \%$. Se a análise se restringir apenas à área do Direito, esse dado corresponde $0,006 \%{ }^{14}$ em relação à população brasileira.

Aquele que por um golpe de sorte - ou talvez azar - resolve se dedicar à dupla vocação científica (docência e pesquisa) ${ }^{15}$, via de regra, começará uma verdadeira via sacra para, em primeiro lugar, tentar compensar os estudos elementares que não teve acesso durante a graduação, simultaneamente à exigência cada vez maior de dedicação e produção científica que em muitos dos casos nunca foi sequer iniciado ${ }^{16}$. Inclusive, a esse respeito existem vários estudos que identificaram a existência de uma patologia relacionada ao estresse no meio acadêmico, conhecido como burnout acadêmico ${ }^{17}$. Não é difícil perceber que os pesquisadores e pesquisadoras também enfrentarão desafios financeiros, já que a demanda é bem maior do que a oferta de bolsas (cujos valores não são, por si só, um grande incentivo) ${ }^{18}$.

No caso das ciências jurídicas, de maneira geral, há uma dissociação bem clara - e por vezes pejorativa - entre o "profissional prático" e o "acadêmico teórico"19, "como se a teoria não iluminasse a ação, e a prática não atualizasse a teoria” ${ }^{20}$. Possivelmente decorrente de uma

14 Conforme GeoCapes, o total de matriculados e titulados na área do Direito é de 11.705 pessoas (Disponível em: <https://geocapes.capes.gov.br/geocapes/\#>. Acesso em 26 jul. 2017).

15 ARAÚJO, Nádia de. Formação do jurista pesquisador: pressupostos e requisitos, técnicas de pesquisa e ensino na pós-graduação. Direito, Estado e Sociedade, n. 14, Rio de Janeiro, 1999. p. 25.

16 SILVA, Talita C. BARDAGI, Marúcia Patta. O aluno de pós-graduação stricto sensu no Brasil: revisão da literatura dos últimos 20 anos. Revista Brasileira de Pós-Graduação, v. 12, n. 29, 2015.

17 SOUZA, Rayssa (et al). A pós-graduação e a síndrome de burnout: estudo com alunos de mestrado em administração. RPCA, Rio de Janeiro, v. 4, n.3, set/ dez, 2010, p. 21-22.

18 No Brasil, as bolsas de estudos para pesquisadores variam de $\mathrm{R} \$ 400,00$ (Iniciação Científica) a $\mathrm{R} \$ 2.200,00$ mensais (doutorado) (Disponível em: <http://www.cnpq.br/no-pais/>. Acesso em 03 abr. 2017).

19 ALMEIDA, Frederico de; SOUZA, André L. D.; CAMARGO, Sarah B. Direito e realidade: desafios para o ensino jurídico. In: GHIRARDI, José G. FEFERBAUM, Marina (org). Ensino do direito em debate: reflexões a partir do $1^{\circ}$ Seminário Jurídico e Formação Docente. São Paulo: Direito GV, 2013.

20 VENTURA, Deisy. Do direito ao método, do método ao direito. In: Daniel Torres de Cerqueira; Roberto Fragale Filho. (Org.). O Ensino Jurídico em 
divisão fictícia entre disciplinas dogmáticas e zetéticas ${ }^{21}$ nos cursos de Direito, onde normalmente o estudante "prático" se aplica às primeiras e tendencialmente se afasta das últimas.

Nesse espaço de disputa ainda é acrescentada uma dificuldade particular: o Direito é uma ferramenta concreta de modificação da sociedade (desde os gestores das instituições públicas até a produção legislativa), o que invariavelmente interferirá no palco de disputa de poder político, econômico e social. Dessa forma, a divisão estabelecida lá na graduação alcança patamares mais elevados com o avanço desses atores na vida social, todavia, a antiga dicotomia permanece, às vezes inflamada em discursos acalorados e ofensivos uns contra os outros.

Há também um claro problema envolvendo o mercado de trabalho que não absorve toda a massa de bacharéis ${ }^{22}$ formados pelos cursos de Direito $^{23}$, fazendo da docência uma via alternativa ou complementar para a renda mensal do profissional. Nesse aspecto, muitas vezes os títulos acadêmicos são mais ostensivos de uma espetaculização ${ }^{24}$ da vida acadêmica, voltados para angariar mais clientes, para a autopromoção ou como símbolo demonstrativo de "conhecimento", do que para uma efetiva contribuição para a produção científica nas ciências jurídicas.

Debate. Campinas: Millennium, 2007. p. 257-292.

${ }^{21}$ Para Tércio Sampaio, as disciplinas zetéticas (Filosofia, Ciência Política, Psicologia Forense, Criminologia, etc.) "tem sua característica principal na abertura constante para o questionamento dos objetos em todas as direções" enquanto as dogmáticas (Direito Penal, Constitucional, Processual Penal, etc.) consideram "certas premissas, em si e por si arbitrárias (isto é, resultantes de uma decisão), como vinculantes para o estudo" (FERRAZ JR., Tercio Sampaio. Introdução ao estudo do Direito. São Paulo: Atlas, 2008. p. 21-28).

SILVA, Talita C. BARDAGI, Marúcia Patta. O aluno de pós-graduação stricto sensu no Brasil: revisão da literatura dos últimos 20 anos. Revista Brasileira de Pós-Graduação, v. 12, n. 29, 2015.

23 Em 2015 o Brasil já "contava com 1.280 Faculdades de Direito, com quase 800 mil advogados inscritos na entidade e cerca de 3 milhões não aprovados no Exame de Ordem" (FREITAS, Vladimir Passos. Excesso de Faculdade de Direito implode o mercado de trabalho. Disponível em: <http://www.conjur. com.br/2015-set-06/segunda-leitura-excesso-faculdades-direito-implodem-mercado-trabalho>. Acesso em 01 mai. 2017).

24 DEBORD, Guy. A sociedade do espetáculo. Rio de Janeiro: Contraponto, 2016. p. 16-17. 
Ocorre que esses não são os únicos desafios do desenvolvimento do pesquisador: há ainda clara diferenciação e disparidade relacionadas com questões raciais e de gênero ${ }^{25}$. A esse respeito, conforme apontado pelo Plano Nacional de Pós-Graduação (PNPG) ${ }^{26}$, houve de maneira geral um crescimento de cursos de pós-graduação no Brasil, e embora o referido Plano não indique a variação por sexo e/ou cor, segundo os dados da pesquisa realizada por Rosemberg e Madsen, no intervalo que compreende entre os anos de 2003 e 2009, essa é a distribuição por cor e sexo:

TABela 15. Distribuição de ESTUdANTES DE MESTRAdo E DOUTORADO POR SEXO E COR/RAÇA, BRASIL 2003 E 2009

\begin{tabular}{|l|r|r|r|r|r|}
\hline & \multicolumn{2}{|c|}{2003 (\%) } & \multicolumn{2}{c|}{2009 (\%) } & Variação (\%) \\
\hline Total & 310.593 & 100,0 & 330.351 & 100,0 & 6,4 \\
\hline Homens brancos & 106.736 & 34,4 & 103.235 & 31,3 & $-3,4$ \\
\hline Mulheres brancas & 141.543 & 45,6 & 148.958 & 45,1 & 5,2 \\
\hline Homens negros & 23.659 & 7,6 & 30.977 & 9,4 & 30,9 \\
\hline Mulheres negras & 33.564 & 10,8 & 41.360 & 12,5 & 23,2 \\
\hline outros & 5.091 & 1,6 & 5.821 & 3,5 & 14,3 \\
\hline
\end{tabular}

Fonte: Tabulações especiais de microdados das PNADs 2003 e $2009 .{ }^{27}$

25 A análise da variação entre o Censo 2000 e 2010 tendo como critério o ensino superior completo e comparando os dados de cor e gênero evidencia que o número de mulheres nele inseridas se manteve superior ao dos homens, enquanto que a população negra, mesmo tendo um aumento significativo na comparação ainda representa uma parcela muito pequena, contrastando com o seu aumento no total geral da população (Disponível em: <http://www. ibge.gov.br/apps/snig/v1/?loc=0\&cat=1,2,3,4,48,128\&ind $=4698>$. Acesso em 03 abr. 2017).

26 De acordo com a informação disponível no site da CAPES, o Plano Nacional da Pós-Graduação 2011-2020 (PNPG) “tem como objetivo definir novas diretrizes, estratégias e metas para dar continuidade e avançar nas propostas para política de pós-graduação e pesquisa no Brasil. Paralelamente a este Plano, está sendo elaborado o novo Plano Nacional de Educação (PNE). De fato, pela primeira vez, um plano nacional de educação contemplará as metas da pós-graduação, isso porque o PNPG será parte integrante do PNE. (Disponível em: <http://www.capes.gov.br/plano-nacional-de-pos-graduacao>. Acesso em: 15 abr. 2017).

27 ROSEMBERG, Fúlvia; MADSEN, Nina. Educação formal, mulheres e gênero no Brasil contemporâneo. In: BARSTED, Leila L; PITANGUY, Jacqueline. O Progresso das Mulheres no Brasil 2003-2010. Brasília: ONU Mulheres, 2011. p. 425. 
Os dados apresentados mostram apenas parcela da realidade, até porque não há nada que indique essa proporção especificamente em cursos de pós-graduação em Direito ou nas ciências criminais. Contudo, nota-se que apesar dos dados apontarem que a presença de mulheres nos cursos de pós-graduação - de maneira geral - seja maior, evidentemente isso não está representado no número de profissionais reconhecidos publicamente (lugar de fala, participação em congressos, publicação de livros, etc. $)^{28}$. Não se trata - como os números revelam de uma desproporção na quantidade de pesquisadores e pesquisadoras, mas nos atores que dominam o campo e estão em evidência no cenário nacional ${ }^{29}$.

Tal fato apenas reforça a ideia de que o panorama jurídico-científico brasileiro - embora se reconheça um movimento recente para mudança dessa realidade - ainda é dominado por uma classe e um gênero bastante específicos, o que obviamente influenciará também nas pautas de pesquisa em desenvolvimento no país. A mesma análise pode ser feita em relação aos homens e mulheres negros, com a agravante de que nesses casos o próprio acesso à pós-graduação, conforme apontado pela pesquisa, é menor, escancarando a desigualdade racial existente nos cursos de pós-graduação no Brasil e o claro predomínio de um perfil bastante específico de pesquisador ${ }^{30}$.

Mas qual a relevância da constatação do perfil do(a) pesquisador(a) nas ciências criminais? Ora, a produção de conhecimento científico, principalmente fruto de uma determinada classe e/ou gênero e/ ou cor influenciará direta ou indiretamente nos problemas e objetos de pesquisa a serem desenvolvidos cientificamente. Afinal, o paradigma contemporâneo das ciências já demonstrou a verdadeira dimensão da

28 Infelizmente, a pesquisadora nas ciências criminais ainda não tem a mesma notoriedade que os pesquisadores do sexo masculino. Facilmente observável na quantidade de obras jurídicas que são divulgadas e utilizadas nos cursos de graduação e pós-graduação no Brasil.

29 VASSAL, Mylène G. P. Aproximação conceitual: Gênero, Direito, Violência contra as mulheres e Direitos Humanos. In: Curso Capacitação em Gênero: acesso à justiça e violência contra as mulheres. Rio de Janeiro: EMERJ, 2013. p. 104-109.

30 SILVA, Marcos A. B. Políticas e práticas contemporâneas sobre relações raciais e a pós-graduação. Revista Brasileira de Pós-Graduação, v. 13, n. 30, 2016. 
relação sujeito-objeto de pesquisa, quebrando com a falsa imparcialidade do pesquisador diante do objeto pesquisado ${ }^{31}$, pois, é obvio, o(a) pesquisador(a) é um ser-no-mundo.

No caso específico das pesquisas em Ciências Criminais (como gênero das espécies Direito Penal, Direito Processual Penal e Criminologia), uma análise que considera o sujeito-pesquisador toma uma dimensão bastante representativa, pois normalmente são atores que estão concretamente envolvidos com o sistema de justiça criminal (Ministério Público, Judiciário, Advocacia, etc.) ou com políticas públicas de segurança (Polícias, Sistema Penitenciário, etc). Mas também representam entidades públicas e privadas com enorme reflexo no cotidiano da sociedade, seja na formação de massa crítica e de pesquisas no âmbito das universidades (e cursos de pós-graduação), seja como dirigentes ou membros de presídios, ONGs, partidos políticos, comitês de assessoramento, etc ${ }^{32}$.

A relevância dessas constatações se dá, principalmente, porque no campo jurídico se opera um fenômeno não experimentado na maioria das outras ciências e que diz respeito à própria essência, ou natureza científica, do Direito versus a sua técnica ${ }^{33}$. Nesse ponto, Bourdieu afirma que o "campo jurídico é o lugar de concorrência pelo monopólio do direito de dizer o direito, quer dizer, a boa distribuição (nomos) ou a boa ordem, na qual se defrontam agentes investidos de competência ao mesmo tempo social e técnica que consiste essencialmente na capacidade reconhecida de interpretar (de maneira mais ou menos livre ou autorizada) um corpus de textos que consagram a visão legítima, justa, do mundo social” ${ }^{34}$.

31 SOUSA SANTOS, Boaventura. Um discurso sobre as ciências. São Paulo: Cortez, 2010. p. 71.

32 BEATO, Cláudio. Criminologia e Segurança Pública. A Pós-Graduação em Criminologia e Segurança Pública no Brasil 2011-2020. In: Fundação Coordenação de Aperfeiçoamento de Pessoal de Nível Superior. Plano Nacional de Pós-Graduação - PNPG 2011-2020. Vol. 2. Brasília: CAPES, 2010. p. 117.

33 A esse respeito, sugere-se a leitura: WARAT, Luís Alberto. Saber crítico e senso comum teórico dos juristas. Revista Sequência. Florianópolis, n. 3, volume 5, p. 48-57, 1982.

34 BOURDIEU, Pierre. Poder simbólico. Lisboa: Edições 70, 2016. p. 220-221. 
Na realidade histórica brasileira, a construção do pensamento jurídico sempre esteve atrelada às tradições lusitanas, uma espécie de legalidade imposta, sem reconhecer adequadamente as práticas já existentes no território colonizado. A análise dessa relação MetrópoleColônia se faz também importante para expor a raiz da dissonância histórica entre a prática e a teoria dos operadores jurídicos no Brasil ${ }^{35}$.

Decorre daí, mas somente após a instalação das primeiras faculdades de Direito no Brasil é que floresce, a divisão entre o "jurista" e o "bacharel". Normalmente voltado para posturas teóricas, abstrações filosóficas e científicas, via de regra afastado da política militante, o primeiro se dedicava a pensar e criar o Direito a partir da dinâmica social ${ }^{36}$ (progressista ou reacionária). Já o "bacharel strictu sensu”, desenvolvia sua atividade prática voltada para a mecânica exegética com grande apego às formulas clássicas, à imutabilidade das estruturas e padrões prefixados, além da identificação com valores conservadores ${ }^{37}$ e do fetichismo com a lei ${ }^{38}$.

Não muito diferente é a realidade contemporânea, cujos discursos de "juristas" e de "bacharéis" parecem cada vez mais distantes um do outro e, para completar, muitas vezes ambos afastados da realidade social. Um dos reflexos relevantes dessa dissonância pode ser caracterizado como apropriação institucional de conceitos, resultado de "tipo de leitura, dos conceitos, construída no interior de marcos institucionais específicos (escolas de direito, tribunais, órgãos legislativos) onde se produzem versões das teorias ajustadas às crenças e, representações e interesses legitimados pelas instituições" ${ }^{39}$.

35 WOLKMER, Antonio C. História do Direito no Brasil. Rio de Janeiro: Forense, 2003. p. 47.

36 Atualmente, a atenção do jurista à dinâmica social, especialmente tratando-se das ciências criminais é condição elementar para o pesquisador, como bem apontado por Alessandro Baratta em Criminologia Crítica e Crítica do Direito Penal.

37 WOLKMER, Antonio C. História do Direito no Brasil. Rio de Janeiro: Forense, 2003. p. 83.

38 DUCE, Mauricio. REGO, Cristián. Proceso Penal. Santiago: Editorial Jurídica de Chile, 2007. p. 14.

39 WARAT, Luís Alberto. Saber crítico e senso comum teórico dos juristas. Revista Sequência. Florianópolis, n. 3, volume 5, p. 48-57, 1982. p. 55. 
E, embora seja majoritariamente aceito no meio jurídico, e também pela população em geral, que um possível caminho para o progresso social, político e econômico se dê por meio da educaçã $0^{40}$, a pesquisa jurídica ainda é tida como de menor importância (até por as vezes não ter "aplicação prática"), o que vai contra a concepção geral e as diretrizes da UNESCO ${ }^{41}$ além da própria Constituição Federal de 1988. Nesse ponto, a pesquisa científica - no nosso caso, jurídica - é uma das bases para uma educação sólida, crítica e produtiva, além de pré-condição para uma educação de qualidade ${ }^{42}$.

Ora, no país que ainda precisa enfrentar desigualdades sociais crônicas e outras demandas como o analfabetismo, a fome, o desempre-

40 Desde o relatório de Faure (1972) elaborado e divulgado com auxílio da UNESCO, já havia uma preocupação de que "a educação não se define mais em relação a um conteúdo determinado que se trata de assimilar, mas concebe-se, na verdade, como um processo de ser que, através da diversidade de suas experiências, aprende a exprimir-se, a comunicar, a interrogar o mundo e a tornar-se sempre mais ele próprio", e nessa sintonia, o relatório Delour (1996), resultado Comissão Internacional sobre Educação para o século XXI (UNESCO), acrescenta que um "dos principais papéis reservados à educação consiste, antes de mais nada, em dotar a humanidade da capacidade de dominar o seu próprio desenvolvimento. Ela deve, de fato, fazer com que cada um tome o seu destino nas mãos e contribua para o progresso da sociedade em que vive, baseando o desenvolvimento na participação responsável dos indivíduos e as comunidades" (WERTHEIN, Jorge. CUNHA, Célio da. Fundamentos da Nova Educação. Brasília: UNESCO, 2000. p. 14 e 21) (grifos do autor).

41 Para elucidar algumas das propostas da UNESCO, o resultado da Declaração Mundial sobre Educação Superior no Século XXI (Conferência de Paris, 1998), indica, entre outras coisas: (i) educar, formar e realizar pesquisas com estrita observância de garantir alta qualidade. Deverá oferecer uma ampla gama de ofertas e opções e assegurar a educação permanente, como também difundir conhecimentos e contribuir para a preservação e difusão das culturas nacionais, regionais, internacionais e históricas, num contexto de pluralismo, diversidade cultural, consolidação dos direitos humanos e desenvolvimento de uma cultura de paz; (ii) Promover o avanço do conhecimento por meio da pesquisa, que constitui uma função essencial de todos os sistemas de educação superior; (iii) A inovação, a interdisciplinaridade e a transdiscipinaridade devem ser fomentadas e reforçadas pela política de incentivo à pesquisa. (WERTHEIN, Jorge. CUNHA, Célio da. Fundamentos da Nova Educação. Brasília: UNESCO, 2000. p. 41-43).

42 WERTHEIN, Jorge. CUNHA, Célio da. Fundamentos da Nova Educação. Brasília: UNESCO, 2000. p. 34. 
go, o abastecimento sanitário, por que investir em pesquisa e pesquisadores(as) - ainda mais jurídica?

Como bem elucidado pelo Fórum de Reflexão Universitária, na década de 1960 um professor universitário, durante alguma reunião de docentes, deveria responder ao questionamento: "Você faz pesquisa?" Nos anos de 1970, a pergunta mudou seu enfoque para "Você tem publicado papers?" Já a realidade do século XXI, marcada por intensas e rápidas transformações no mundo (globalização, sociedade do risco, controle, internet, velocidade, etc.) apresenta para o mesmo professor outras perguntas: Quantos trabalhos você publicou este ano? Qual o fator de impacto das revistas nas quais você publica? E mais recentemente, "Objetivamente sua pesquisa serve para quê?" 43

Hoje se vivencia um crescimento exponencial de cursos de pós-graduação lato e stricto sensu, além de encontros científicos $\left(\mathrm{CONPEDI}{ }^{44}\right)$, criação de revistas científicas, como a Revista Brasileira de Direito Processual Penal - RBDPP, especializadas em determinadas áreas, com corpo de avaliadores, corpo editorial e comitês científicos compostos por pesquisadores(as) qualificados(as). Discute-se ciência jurídica nas redes sociais, nos grupos de pesquisas, etc.

Mas nem sempre foi assim. De fato, o começo do desenvolvimento do ensino superior no Brasil está diretamente relacionado com a vinda da família real em 1808, mas essa formação era constituída por um caráter eminentemente profissionalizante, prático e emergencial $^{45}$. Pode-se afirmar que é principalmente no final do século XIX que começam a estruturar alguns centros de ensino e pesquisa no Brasil,

43 VERCOSI, Aníbal et al. Os desafios da pesquisa no Brasil. Uma contribuição de docentes da Unicamp para o debate. Caderno Temático, Campinas, $\mathrm{n}^{\mathrm{o}} 12$, ano I, 2002. p. 3.

44 O Conselho Nacional de Pesquisa e Pós-Graduação em Direito (CONPEDI), criado em 1989, é uma instituição que fomenta a pesquisa jurídica no Brasil, principalmente com a realização de eventos científicos, e atualmente tem a proposta de internacionalizar a pesquisa e o desenvolvimento da pós-graduação do Brasil no exterior. (Disponível em: <http://www.conpedi.org.br/ quemsomos/>. Acesso em 15 abr. 2017).

45 ALFONSO-GOLDFARB, Ana Maria. FERRAZ, Márcia H. M. Raízes históricas da difícil equação institucional da ciência no Brasil. São Paulo em Perspectiva, vol. 16, no 3, 2002. p. 6. 
atraindo investimentos específicos e importação de profissionais da educação para esse processo ${ }^{46}$.

Todavia, o desenvolvimento científico implica não apenas no ensino e pesquisa, mas também em processos de divulgação e aplicação do conhecimento adquirido ${ }^{47}$, proporcionando à Ciência "maior autonomia, relevância, liderança local e, sobretudo, com implicações conseqüentes(sic) para o desenvolvimento científico, tecnológico, social e cultural" ${ }^{48}$. Verdadeiramente, a pesquisa científica e seu desenvolvimento estão relacionados não apenas com incentivo financeiro - embora seja um fator primordial - mas está atrelada a uma visão de mundo segundo a qual a pesquisa científica é um fator de desenvolvimento social, político, econômico, cultural, sanitário e tantos outros e deve constar na agenda dos dirigentes do país.

A esse respeito, a chegada do século XXI foi acompanhada por uma considerável reforma no tratamento da pesquisa no Brasil, resultado de políticas públicas direcionadas para seu fomento seguidas por estruturação institucional de órgãos públicos para a gestão ${ }^{49}$ e aplicação desses recursos ${ }^{50}$. Segundo estatísticas de 2015, o Brasil conta com 91 programas de pós-graduação ${ }^{51}$ stricto sensu na área de avaliação "Direito", todavia, esse dado por si só não exprime a totalidade das pes-

46 PEREZ, José Fernando. Pesquisa: construção de novos paradigmas. São Paulo em Perspectiva, vol. 16, $\mathrm{n}^{\circ}$ 4, 2002. p. 30.

47 ALFONSO-GOLDFARB, Ana Maria. FERRAZ, Márcia H. M. Raízes históricas da difícil equação institucional da ciência no Brasil. São Paulo em Perspectiva, vol. 16, no 3, 2002. p. 4.

48 VERCOSI, Aníbal et al. Os desafios da pesquisa no Brasil. Uma contribuição de docentes da Unicamp para o debate. Caderno Temático, Campinas, $\mathrm{n}^{\circ} 12$, ano I, 2002. p. 4.

49 O Conselho Nacional de Desenvolvimento Científico e Tecnológico (CNPq) foi criado em 1951, e está voltado para a "formulação e condução das políticas de ciência, tecnologia e inovação”, cuja missão institucional está orientada para "fomentar a Ciência, Tecnologia e Inovação e atuar na formulação de suas políticas, contribuindo para o avanço das fronteiras do conhecimento, o desenvolvimento sustentável e a soberania nacional". (Disponível em: <http://cnpq.br/apresentacao_institucional/>. Acesso em 15 abr. 2017).

50 GUIMARÃES, Reinaldo. Pesquisa no Brasil: reforma tardia. São Paulo em Perspectiva, vol. 16, $\mathrm{n}^{\circ} 4,2002$. p. 41.

51 Disponível em: <http://geocapes.capes.gov.br/geocapes2/>. Acesso em 15 abr. 2017. 
quisas jurídicas, já que é da sua própria essência a adequação a programas que podem estar relacionados com a área de História, Filosofia, Ciências Sociais, Economia, etc.

Um outro ponto a ser considerado ao se analisar a pesquisa jurídica no Brasil diz respeito ao próprio objeto e a considerável diferença com as demais áreas do conhecimento. Notoriamente existe certa discrepância no desenvolvimento da pesquisa jurídica e as demais áreas (biológicas ou exatas, por exemplo), que pode ter influência de fatores histórico-culturais, mas paulatinamente vem sendo construída uma nova realidade, principalmente em razão da ampliação no acesso a programas de pós-graduação, assim como a internacionalização dos(as) pesquisadores(as), seguida pela valorização financeira e pelo status social do(a) pesquisador(a) em ciências jurídicas.

De maneira geral, e apenas para evidenciar a atual configuração da pesquisa em ciências criminais no Brasil, em consulta na base de dados do Diretório de Grupos de Pesquisa no Brasil, a busca pelo termo "ciências criminais" conta com 19 registros, o termo "direito processual penal" aponta 15 registros, o termo "direito penal" apresenta consideráveis 123 registros e 65 para o termo "criminologia" 52 , totalizando 242 grupos de pesquisa abordando esses temas. Em relação à possibilidade de publicação da produção científica no Brasil, no banco de dados disponível pelo Portal Periódicos CAPES, na subárea do conhecimento Direito, existem $126^{53}$ registros de revistas científicas (nacionais e internacionais) reconhecidas e qualificadas (QUALIS), representando o $3^{\circ}$ lugar em número de revistas em comparação com as demais áreas ${ }^{54}$.

52 Disponível em: <http://dgp.cnpq.br/dgp/faces/consulta/consulta_parametrizada.jsf $>$. Acesso em 15 abr. 2017.

53 Disponível em: <http://www.periodicos.capes.gov.br/index.php?option=com_pmetabusca $\& \mathrm{mn}=70 \& \mathrm{smn}=78 \& \mathrm{sfx}=$ buscaRapida $\&$ type $=$ p $\&$ Itemid=120>. Acesso em 27 jul. 2017.

54 Existem 752 registros de periódicos no banco de dados, divididos da seguinte forma: (i) Administração de empresas, administração pública e contabilidade: 211; (ii) Economia: 167; (iii) Direito: 126; (iv) Ciências Sociais Aplicadas (geral): 89; e (v) Ciência da informação: 86 (Disponível em: <http://www. periodicos.capes.gov.br/index.php?option=com_pmetabusca\&mn=70\&sm$\mathrm{n}=78 \&$ sf $=$ =buscaRapida\&type $=$ p\&Itemid=120>. Acesso 27 jul. 2017). 
Embora apenas o número de grupos de pesquisa e de revistas científicas não evidencie por si só a qualidade da produção científica jurídica no Brasil, esse dado revela, para dizer o mínimo, uma preocupação e dedicação às discussões científicas relacionadas com essa área, sendo que a produção científica acaba sendo consequência dos avanços dessas pesquisas.

Conforme já exposto, o incremento da pesquisa científica, mais especificamente a pesquisa em ciências criminais, deve ser acompanhado de mecanismos para divulgação e publicação dos resultados obtidos em um mundo em constante mutação e marcado pela velocidade. Para os que entendem estarmos diante da hipermodernidade ${ }^{55}$, concretamente vivenciamos o deslocamento do centro gravitacional da temporalidade do futuro para o presente ${ }^{56}$, o que gera reflexos diretos na ânsia por mais informação (de qualidade), inovação na forma de divulgação e discussão dos temas relacionados com as ciências criminais.

E é exatamente nesse ponto que a RBDPP se insere, buscando "fomentar a produção e divulgação de conhecimento científico relacionado ao direito processual penal, a Revista Brasileira de Direito Processual Penal tem como objetivo a publicação de textos científicos sobre temas que envolvem o direito processual penal, desde uma perspectiva interdisciplinar, abrindo espaço para o diálogo com outras áreas do direito e os variados campos do conhecimento ligados às ciências criminais, como a psicanálise, a filosofia, a sociologia, antropologia, etc" ${ }^{57}$.

Sem perder de vista as dificuldades inerentes à atividade científica, a realidade contemporânea se mostra favorável para a dedicação à pesquisa, talvez ainda carente de um alinhamento (também reconhecimento) por parte da sociedade e demais operadores do Direito, da

55 Segundo Lipovetsky, vive-se uma época diferente da ruptura moderna, marcada principalmente pelo presenteísmo cuja marca é a "cultura do mais rápido e do sempre mais: mais rentabilidade, mais desempenho, mais flexibilidade, mais inovação" (LIPOVETSKY, Guiles. Os tempos hipermodernos. São Paulo: Editora Barcarolla, 2004. p. 57).

56 LIPOVETSKY, Guiles. Os tempos hipermodernos. São Paulo: Editora Barcarolla, 2004. p. 59.

57 Disponível em <http://www.ibraspp.com.br/revista/index.php/RBDPP/ about/editorialPolicies\#focusAndScope>. Acesso em 15 abr. 2017. 
importância de se buscar - longe do idealismo utópico - a conformação da teoria e práticas jurídicas ${ }^{58}$. A prática jurídica isolada da teoria corre o risco se tornar mero instrumento a serviço de interesses políticos ou econômicos ${ }^{59} \mathrm{e}$, por sua vez, a teoria sem aderência prática pode permanecer na torre de marfim e pouco poderá auxiliar na compreensão do mundo em sociedade ${ }^{60}$.

Aí está assentado o importante papel de Revistas Científicas especializadas em determinados campo para promover o debate científico da dinâmica das ciências criminais buscando iluminar os inúmeros pontos cegos ainda presentes na contemporaneidade. Afinal, como bem colocada a reflexão feita por Gomes Canotilho no prefácio da obra O ponto cego do Direito, de Rui Cunha Martins, "o ponto cego é privilégio de quem vê" ${ }^{61}$.

\section{REFERÊNCIAS BIBLIOGRÁFICAS:}

ALFONSO-GOLDFARB, Ana Maria. FERRAZ, Márcia H. M. Raízes históricas da difícil equação institucional da ciência no Brasil. São Paulo em Perspectiva, vol. $16, n^{\circ} 3,2002$.

ALMEIDA, Frederico de; SOUZA, André L. D.; CAMARGO, Sarah B.. Direito e realidade: desafios para o ensino jurídico. In: GHIRARDI, José G. FEFERBAUM, Marina (org). Ensino do direito em debate: reflexões a partir do $1^{\circ}$ Seminário Jurídico e Formação Docente. São Paulo: Direito GV, 2013.

${ }^{58}$ FILHO, Roberto F. VERONESE, Alexandre. A pesquisa em Direito: diagnóstico e perspectivas. Revista Brasileira de Pós-Graduação, v. 1, n. 2, nov. 2004.

59 A esse respeito, Warat sugere dois caminhos para melhor compreender o poder das significações no Direito a partir de análise epistemológicas: “a) através de uma reflexão sobre a relação do sistema de conotação com a prática jurídica e, b) através de uma leitura preocupada com a explicitação das funções sociais do saber jurídico". Ademais, propõe-se a substituição do princípio do egocentrismo textual pelo princípio da heteronímia significativa (WARAT, Luís Alberto. Saber crítico e senso comum teórico dos juristas. Revista Sequência. Florianópolis, n. 3, volume 5, p. 48-57, 1982. p. 56.)

60 Para Zaffaroni, "se alguém pretende fazer uma criminologia teórica pura, sem consequências práticas - sem aplicação -, é melhor que fechem-se a porta e deixemos sozinho em seu escritório" (tradução do autor). (ZAFFARONI, Eugenio R. La cuestión criminal. Buenos Aires: Planeta, 2012. p. 202).

${ }^{61}$ CANOTILHO, José G. Prefácio. In: MARTINS, Rui Cunha. O ponto cego do Direito. The Brazilian Lessons. São Paulo: Atlas, 2013. p. XII. 
ARAÚJO, Nádia de. Formação do jurista pesquisador: pressupostos e requisitos, técnicas de pesquisa e ensino na pós-graduação. Direito, Estado e Sociedade, n. 14, Rio de Janeiro, 1999.

BALBACHEVSKY, Elizabeth. A pós-graduação no Brasil: novos desafios para uma política bem-sucedida. In: BROCK, Colin. SCHWARTZMAN, Simon (org). Os desafios da educação no Brasil. Rio de Janeiro: Editora Nova Fronteira, 2005.

BARATTA, Alessandro. Criminologia crítica e Crítica do Direito Penal. Introdução à sociologia do Direito Penal. Rio de Janeiro: Revan, 2014.

BEATO, Cláudio. Criminologia e Segurança Pública. A Pós-Graduação em Criminologia e Segurança Pública no Brasil 2011-2020. In: Fundação Coordenação de Aperfeiçoamento de Pessoal de Nível Superior. Plano Nacional de Pós-Graduação - PNPG 2011-2020, vol. 2. Brasília: CAPES, 2010.

BOURDIEU, Pierre. Poder simbólico. Lisboa: Edições 70, 2016.

CANOTILHO, José G. Prefácio. In: MARTINS, Rui Cunha. O ponto cego do Direito. The Brazilian Lessons. São Paulo: Atlas, 2013.

DEBORD, Guy. A sociedade do espetáculo. Rio de Janeiro: Contraponto, 2016.

DUCE, Mauricio. REGO, Cristián. Proceso Penal. Santiago: Editorial Jurídica de Chile, 2007.

FERRAZ JR., Tercio Sampaio. Introdução ao estudo do Direito. São Paulo: Atlas, 2008.

FILHO, Roberto F. VERONESE, Alexandre. A pesquisa em Direito: diagnóstico e perspectivas. Revista Brasileira de Pós-Graduação, v. 1, n. 2, nov. 2004.

FINKEL, Don. Dar classe con la boca cerrada. Valência: Publicacions de la Universitat de Valência, 2000.

FREITAS, Vladimir Passos. Excesso de Faculdade de Direito implode o mercado de trabalho. Disponível em: <http://www.conjur.com.br/2015-set-06/segundaleitura-excesso-faculdades-direito-implodem-mercado-trabalho $>$. Acesso em: 01 mai. 2017.

GIACOMOLLI, Nereu. Pensar, aprender e transmitir Direito Processual Penal. Boletim Informativo IBRASPP, Porto Alegre, n. 07, 2014

GUIMARÃES, Reinaldo. Pesquisa no Brasil: reforma tardia. São Paulo em Perspectiva, vol. 16, $\mathrm{n}^{\circ}$ 4, 2002.

HAWKING, Stephen. Uma breve história do tempo. Rio de Janeiro: Intrínseca, 2015.

HOLANDA, Sérgio B. Raízes do Brasil. São Paulo: Companhia das Letras, 2014. 
LIPOVETSKY, Guiles. Os tempos hipermodernos. São Paulo: Editora Barcarolla, 2004.

MORIN, Edgar. Ciência com consciência. Rio de Janeiro: Bertrand Brasil, 2010.

PEREZ, José Fernando. Pesquisa: construção de novos paradigmas. São Paulo em Perspectiva, vol. 16, $\mathrm{n}^{\mathrm{o}}$ 4, 2002.

ROSEMBERG, Fúlvia; MADSEN, Nina. Educação formal, mulheres e gênero no Brasil contemporâneo. In: BARSTED, Leila L; PITANGUY, Jacqueline. O Progresso das Mulheres no Brasil 2003-2010. Brasília: ONU Mulheres, 2011.

SILVA, Marcos A. B. Políticas e práticas contemporâneas sobre relações raciais e a pós-graduação. Revista Brasileira de Pós-Graduação, v. 13, n. 30, 2016.

SILVA, Talita C. BARDAGI, Marúcia Patta. O aluno de pós-graduação stricto sensu no Brasil: revisão da literatura dos últimos 20 anos. Revista Brasileira de Pós-Graduação, v. 12, n. 29, 2015.

SOUSA SANTOS, Boaventura. Um discurso sobre as ciências. São Paulo: Cortez, 2010.

SOUZA, Rayssa (et al). A pós-graduação e a síndrome de burnout: estudo com alunos de mestrado em administração. RPCA, Rio de Janeiro, v. 4, n.3, set/dez, 2010.

VASSAL, Mylène G. P. Aproximação conceitual: Gênero, Direito, Violência contra as mulheres e Direitos Humanos. In: Curso Capacitação em Gênero: acesso à justiça e violência contra as mulheres. Rio de Janeiro: EMERJ, 2013.

VENTURA, Deisy. Do direito ao método, do método ao direito. In: Daniel Torres de Cerqueira; Roberto Fragale Filho. (Org.). O Ensino Jurídico em Debate. Campinas: Millennium, 2007. p. 257-292.

VERCOSI, Aníbal et al. Os desafios da pesquisa no Brasil. Uma contribuição de docentes da Unicamp para o debate. Caderno Temático, Campinas, $n^{\circ} 12$, ano I, 2002.

WARAT, Luís Alberto. Saber crítico e senso comum teórico dos juristas. Revista Sequência. Florianópolis, n. 3, volume 5, p. 48-57, 1982.

WERTHEIN, Jorge. CUNHA, Célio da. Fundamentos da Nova Educação. Brasília: UNESCO, 2000.

WOLKMER, Antonio C. História do Direito no Brasil. Rio de Janeiro: Forense, 2003.

ZAFFARONI, Eugenio R. La cuestión criminal. Buenos Aires: Planeta, 2012. 


\section{Informações adicionais e declarações do autor (integridade científica)}

Declaração de conflito de interesses (conflict of interest declaration): o autor confirma que não há conflitos de interesse na realização das pesquisas expostas e na redação deste editorial.

Declaração de autoria (declaration of authorship): todas e somente as pessoas que atendem os requisitos de autoria deste editorial estão listadas como autores.

Declaração de ineditismo e originalidade (declaration of originality): o autor assegura que o texto aqui publicado não foi divulgado anteriormente em outro meio e que futura republicação somente se realizará com a indicação expressa da referência desta publicação original; também atesta-se que não há plágio de terceiros ou autoplágio.

\section{COMO CITAR ESTE EDITORIAL:}

GALÍCIA, Caíque R. Editorial: O pesquisador e a pesquisa em ciências criminais na contemporaneidade. Revista Brasileira de Direito Processual Penal, Porto Alegre, vol. 3, n. 3, p. 769-787, set./dez. 2017. https://doi.org/10.22197/rbdpp.v3i3.100

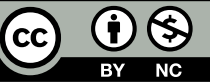

Esta obra está licenciada com uma Licença Creative Commons Atribuição-NãoComercial 4.0 Internacional. 